\title{
Do farmers support cheetah Acinonyx jubatus conservation in Botswana despite livestock depredation?
}

\author{
Moses Seleb atso, Stein R. Moe and Jon E. Swenson
}

\begin{abstract}
In Botswana a large cheetah population, with higher densities outside than inside protected areas, increases the potential of conflict with farmers because of livestock depredation. However, information on the extent of livestock depredation by cheetah and farmers' perceptions of this has been lacking. We interviewed 123 farmers in Ghanzi District, Botswana, to assess problems caused by cheetah depredation of livestock and farmers' attitudes towards cheetah conservation beyond protected areas. Despite livestock losses, farmers generally supported efforts to conserve cheetah, with support increasing with level of education. However, farmers felt that cheetah should not be conserved within farming areas. Land-use practice and culture related to land use played a major role in determining the level of farmers' support for cheetah conservation beyond protected areas: high on private farms, moderate in wildlife management areas, and low on communal lands. Underreporting by farmers led to underestimation by the Department of Wildlife and National Parks of the extent and nature of cheetah conflict with farmers. This study suggests that education and active involvement of farmers in planning and decision-making concerning cheetah management would enhance farmers' positive perception of cheetah conservation beyond protected areas.
\end{abstract}

Keywords Acinonyx jubatus, Botswana, cheetah, coexistence, farmers, Ghanzi District, human-wildlife conflict, livestock losses.

This paper contains supplementary material that can be found online at http://journals.cambridge.org

\section{Introduction}

\footnotetext{
7 he cheetah Acinonyx jubatus is categorized as Vulner1 able on the IUCN Red List (IUCN, 2007), with an estimated declining world population of $<10$,000 mature individuals and $<1,000$ per subpopulation. Cheetahs oc-

Moses Selebatso*, Stein R. Moe (Corresponding author) and Jon E. Swenson Department of Ecology and Natural Resource Management, Norwegian University of Life Sciences, P.O. Box 5003, 1432 Ås, Norway. E-mail stein.moe@umb.no

${ }^{*}$ Current address: Department of Wildlife and National Parks, P.O. Box 131, Gaborone, Botswana.

Received 14 December 2006. Revision requested 3 February 2007.

Accepted 25 June 2007.
}

cupy a wide range of habitats from open savannah to dense woodland habitats (Purchase \& du Toit, 2000; Broomhall et al., 2003; Durant et al., 2004), with occurrence generally positively influenced by density of its main prey (Broomhall et al., 2003) and negatively by the distribution of lions Panthera leo (Laurenson, 1994; Durant, 1998; Durant et al., 2004). The cheetah's main prey are small to medium size antelopes, mainly impala Aepyceros melampus and springbok Antidorcas marsupialis, as well as young of large antelopes (Purchase \& du Toit, 2000; Broomhall et al., 2003; Marker et al., 2003d) and sheep and goats (MarkerKraus et al., 1996; Marker et al., 2003d; Patterson et al., 2004).

The possible causes of low cheetah numbers are loss of habitat to agriculture and human development, poaching of both cheetah and their prey species (Mills, 1991; Caro \& Durant, 1995) and persecution by farmers in defence of livestock (Mills, 1991; Marker et al., 2003a,b). Another limiting factor is cub mortality from sympatric predators such as lions (Laurenson, 1994; Durant, 1998; Kelly \& Durant, 2000; Durant et al., 2004).

Cheetah home ranges can exceed $1,500 \mathrm{~km}^{2}$ (Marker, 2002), and such large spatial requirements mean that many protected areas are too small to provide functional ecosystems for cheetahs (Witmer et al., 1995; Purchase \& du Toit, 2000). Thus, areas beyond protected areas are vital for their persistence. Botswana's cheetah population is estimated to be $1,000-1,500$ individuals (i.e. c. $10 \%$ of the total African population), with higher populations outside protected areas, particularly on the freehold farms in Ghanzi District (Marker, 2000). These cheetahs outside protected areas are often in conflict with farmers.

In Botswana the Department of Wildlife and National Parks is responsible for the compensation scheme for livestock depredation by wild animals. In 1997 the Department's compensation scheme excluded livestock losses to cheetah and other species that were not listed as 'dangerous' in the Botswana Wildlife Conservation and National Parks Act No. 28 of 1992 (Botswana Government Gazette, 1996). Because many were killed by farmers, the killing of cheetah was prohibited in 2000 (Botswana Government Gazette, 2000). The exclusion of depredation by cheetah from compensation and the ban on killing of problem cheetah may have contributed to low tolerance by farmers.

The aim of this study was to explore alternative ways to facilitate cheetah management outside protected areas by 
documenting the problem of livestock depredation by cheetah and the perception of farmers towards cheetah conservation. Specifically we address the following questions: (1) What is the level of conflict between farmers and cheetah? (2) Do farmers support cheetah conservation beyond the boundaries of protected areas? (3) What are the management implications of compensating for livestock losses caused by cheetah?

\section{Study area}

The study was conducted in the $117,910 \mathrm{~km}^{2}$ Ghanzi District, south-west Botswana, which is part of the Kalahari ecosystem (Fig. 1). The area is hot and dry with temperatures of $-5-43^{\circ} \mathrm{C}$, and a mean total annual rainfall of $400 \mathrm{~mm}$, which falls between October and April (Thomas, 2002). Common herbivore species include ungulates such as eland Taurotragus oryx, blue wildebeest Connochaetes taurinus, gemsbok Oryx gazella and springbok. Predators include lion, leopard Panthera pardus, cheetah, wild dog Lycaon pictus, spotted hyaena Crocuta crocuta, brown hyaena Hyaena brunnea and black-backed jackal Canis mesomelas.

The human population of Ghanzi District is c. 34,000, $>66 \%$ of whom live in Ghanzi town and the main villages on the communal lands, and the rest in Central Kalahari Game Reserve, wildlife management areas, and freehold farms. The communal land makes up $16 \%$ of the District, private freehold farms $18 \%$, wildlife management areas $14 \%$, and Central Kalahari Game Reserve 44\% (DLUPU, 1995; Fig. 1). The wildlife management areas are multiple-use areas that combine wildlife conservation with economic ventures for rural communities (GoB, 1992). Currently the wildlife management areas in the district are either in the process of, or already are, being utilized by local communities for nature conservation and income generation (DWNP, 2004). Eight local communities, mostly of the Basarwa or San people, in the wildlife management areas have each been allocated $20 \times 20 \mathrm{~km}$ of land for farming and small-scale industrial projects (DLUPU, 1995; Twyman, 2002). The remaining part of the district is composed of c. 200 freehold farms and communal land. Most of the freehold farms are fenced and pastoral, with cattle and game farming the main activities. Farmers on communal land keep both cattle and small stock on open ranges (DLUPU, 1995).

\section{Methods}

We reviewed records of predator problems reported to the Department of Wildlife and National Parks offices in Ghanzi during 1995-2005. We interviewed 123 farmers between June and October 2005 using a questionnaire (Appendix) to determine their perceptions of cheetah conservation outside protected areas. The questionnaire had both open-ended and closed questions. Land-use zones were used to categorize the respondents: private farms, communal lands, and wildlife management areas. Farmers in each zone were selected randomly according to household, cattle post, or farm. Information on tribe, employment, educational background, and number and type of livestock owned was also collected. The tribes interviewed were Bakgalagadi, Baherero, Basarwa and others (including ethnic groups not indigenous to the area). The following information was collected from farmers: ranking of problem predators, previous livestock losses to cheetah, distinction between kills by cheetah and other predators, proper identification or description of cheetah and their tracks and sightings, preventative methods used to alleviate livestock losses caused by cheetah, and external assistance needed from other organizations. Farmers were finally asked if they would support cheetah conservation.

To determine whether all livestock losses reported by farmers to have been caused by cheetahs in 2005 had been recorded, we made random follow-ups of farmers in January 2006 to determine if they had reported their losses

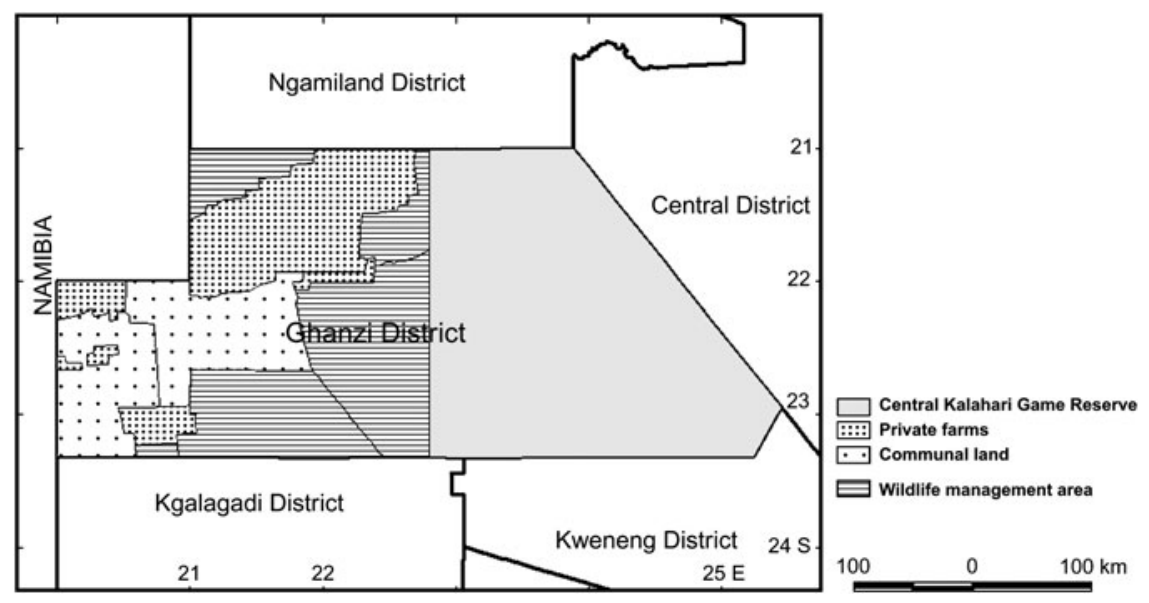

FIG. 1 The four land-use zones in Ghanzi District, Botswana. 
and contacted the Department of Wildlife and National Parks.

Responses from the open-ended questions were grouped or summarized according to their similarities. These include livestock numbers, identification of cheetah and their kills, reasons for not reporting livestock kills by cheetah, the value of the cheetah to farmers, and their reason for supporting or not supporting cheetah conservation. Multiple binary logistic regression was used to determine the relationship between farmers' perception towards cheetah conservation and farmers' educational background, age, tribe, land use, form of employment, type of livestock owned, and distances from the protected areas. Other analyses were performed using standard parametric statistical tests. Minitab v. 14.0 was used for all statistical analyses.

\section{Results}

\section{Level of conflict between farmers and cheetah}

Most cheetah sightings by farmers occurred on private farms $(51 \%)$, followed by communal lands $(35 \%)$ and wildlife management areas $\left(14 \% ; \chi^{2}=14.42, \mathrm{P}=0.001\right)$. Thirty-five percent of farmers lost livestock to cheetah annually, and farms with game most often lost livestock $\left(\chi^{2}=35.08, \mathrm{P}<0.001\right)$. Calves, goats, small game and sheep were the main prey taken by cheetah. The leopard was ranked as the most frequent livestock predator and the cheetah fourth (Fig. 2). Sixty percent of the farmers who ranked cheetah among the top two problematic predators were private farmers. The data from the Department of Wildlife and National Parks also ranked the leopard as the most frequent livestock predator, followed by wild dog, lion, jackal and cheetah (Fig. 3).

Thirty-nine percent of the farmers who reported livestock losses to cheetah did not know when the depredation had taken place. Forty-one percent of the farmers reported

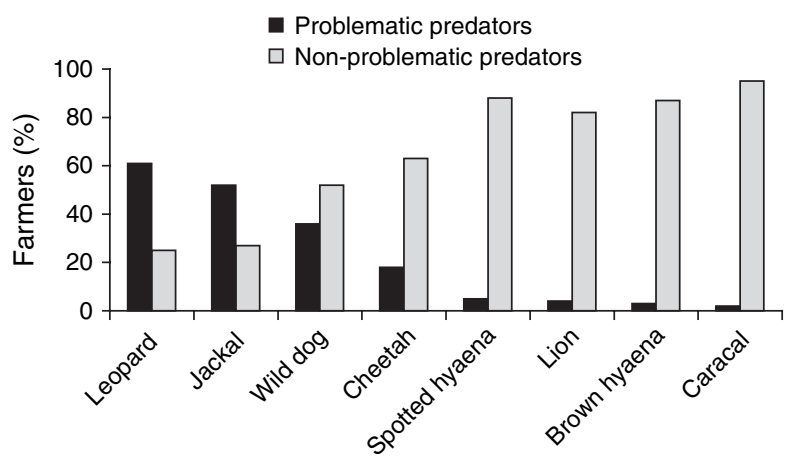

FIG. 2 Percentage of farmers $(n=123)$ ranking mammalian predators as problematic or non-problematic on their farms in Ghanzi District (Fig. 1).

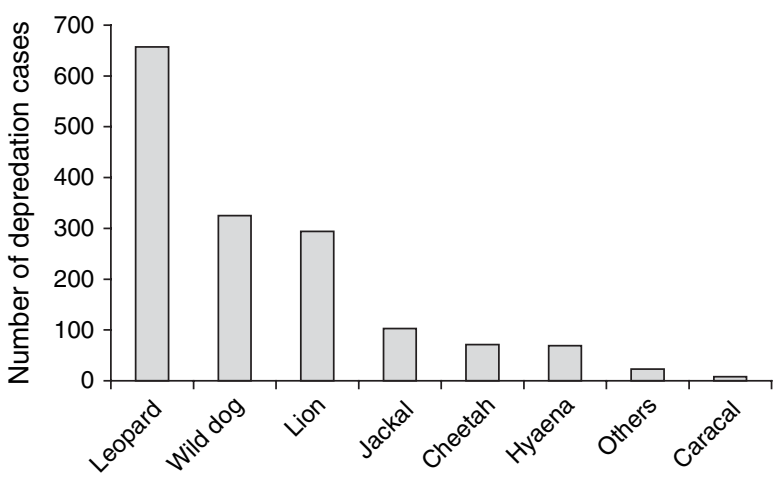

FIG. 3 Total number of livestock depredations by large predator species reported to the Department of Wildlife and National Parks during 1995-2005 in Ghanzi District (Fig. 1).

that it occurred during the day, $15 \%$ at night, and $5 \%$ either during the day or night. Thirty-eight percent of the respondents kraaled (a predator proof fence or thorned bush enclosure) both cattle and small stock at night, $45 \%$ kraaled cattle during the day and small stock at night, and $16 \%$ never kraaled. Two-thirds $(67 \%)$ of the farmers had neither guard dogs nor human herders, $21 \%$ had guard dogs, $7 \%$ had human herders and $4 \%$ had both human herders and guarding dogs. Only $3 \%$ of the farmers reported that losses occurred while dogs guarded livestock. However, $20 \%$ of the farmers reported losses of game animals that could not be guarded with dogs.

\section{Farmers' views of cheetah conservation}

Most farmers ( $76 \%)$ supported efforts to conserve cheetah, $17 \%$ did not and $7 \%$ were neutral. Of the variables analysed, only educational background was significantly, and positively, related to the farmer's support of cheetah conservation in general $(\mathrm{G}=15.83, \mathrm{df}=2, \mathrm{P}<0.001$; Fig. 4). At all education levels the majority of farmers supported cheetah conservation. Farmers with an educational background above primary level were more supportive than those with only primary education $(\mathrm{P}=0.02)$, and those who never

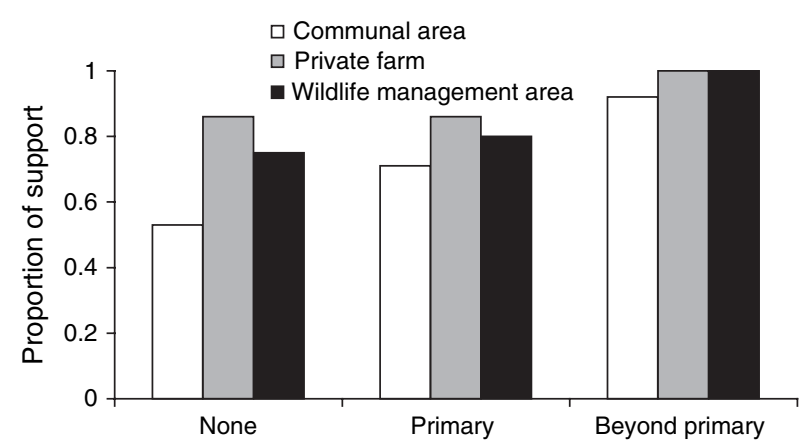

FIG. 4 Relationship between education level and farmers' support for cheetah conservation in Ghanzi District (Fig. 1). 
went to school $(\mathrm{P}=0.005)$, but there was no difference in support between farmers with primary education and those with a lower educational background $(\mathrm{P}=0.49)$. Although land-use type had no significant effect on the farmers' perception of cheetah conservation $(\mathrm{P}=0.07)$, farmers' support tended to increase from communal to private farmers, and all farmers with game (19.5\%) supported cheetah conservation (Fig. 5). When specifically asked about conservation beyond protected areas, the proportion of farmers supporting cheetah conservation decreased from 76 to $47 \%$ and those who were negative increased from 17 to $41 \%$ (Fig. 5). Only land-use type and tribe had significant effects on farmers' perceptions of cheetah conservation beyond protected areas $(\mathrm{P}<0.001)$. Private farmers' support for cheetah conservation outside protected areas was similar to that of farmers in wildlife management areas $(\mathrm{P}=0.23)$, and significantly higher than those on communal lands $(P=0.03)$. The support of farmers in wildlife management areas was not significantly different from that of communal land farmers ( $\mathrm{P}=0.57$; Fig. 6). The Baherero and Bakgalagadi were negative towards cheetah conservation beyond protected areas, whereas the Basarwa and others (mainly non-indigenous farmers) were positive. However, the difference between the Basarwa and the Bakgalagadi was not significant $(P=0.26)$. Although there was no significant relationship $(\mathrm{P}>0.05)$ between the type of livestock owned and farmers' perceptions, $79 \%$ of farmers who had game on their farms supported cheetah conservation beyond protected areas, compared with $39 \%$ for farmers without game.

Almost all respondents who generally did not support cheetah conservation claimed that it kills or is a threat to livestock. Although $67 \%$ of the farmers who were not supportive did not report any previous loss to cheetah, $34 \%$ of those who had experienced previous loss were, nevertheless, supportive of cheetah conservation. Most of the farmers who supported cheetah conservation reasoned that the cheetah is valuable for tourism and that it is one of

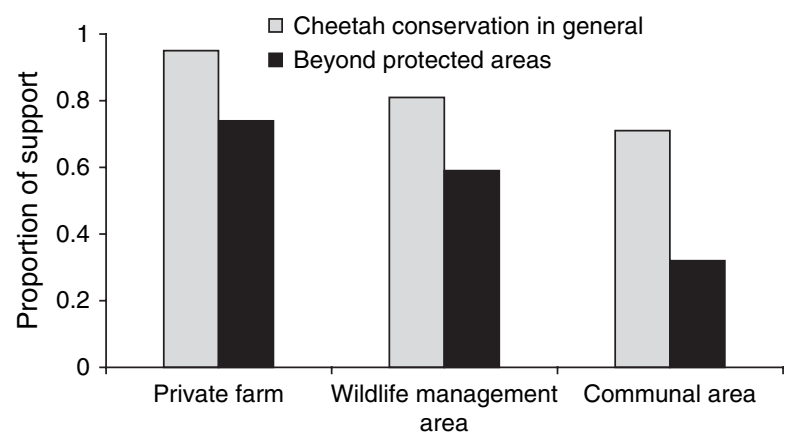

FIG. 5 Comparison of the proportion of farmers supporting cheetah conservation in general and cheetah conservation beyond protected areas in relation to the farmers' land use in Ghanzi District (Fig. 1).

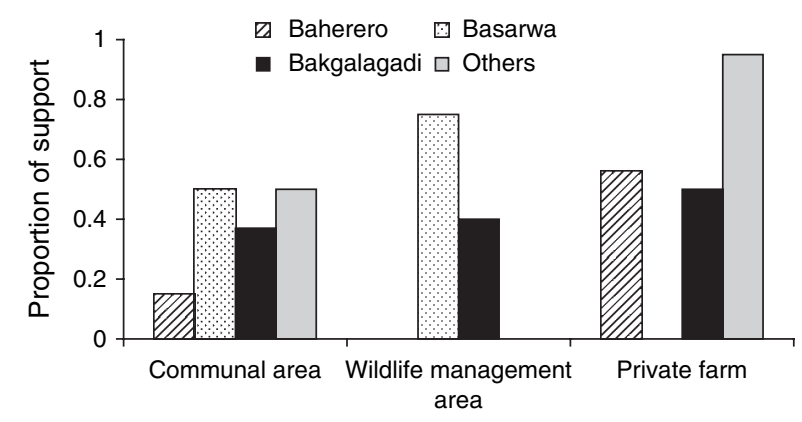

FIG. 6 The relationship between tribe and land-use type and farmers' support for cheetah conservation outside protected areas. Some tribes were not represented in all areas.

the less problematic or dangerous predators of those found in the area.

\section{Management implications of compensation}

A total of 71 cases of depredations by cheetah were reported to the Department of Wildlife and National Parks during 1995-2005 (Fig. 7). More cases of cheetah depredations were reported when compensation was given (1995, 1996 and 2005) than when compensation was not given (1997-2004; $t=3.95, \mathrm{df}=9, \mathrm{P}<0.01)$. Sixty-five percent of the farmers who had lost livestock to cheetah did not report some or all the cases because there was no compensation (23\%), the Parks' offices were too far away (18\%), the depredation evidence was damaged (36\%), or the losses were negligible $(23 \%)$.

\section{Discussion}

The cheetah was ranked as the fourth most problematic predator in Ghanzi District. One-third of the farmers reported losing livestock to cheetah each year, and $10 \%$ of the farmers considered cheetah to be an economic threat to

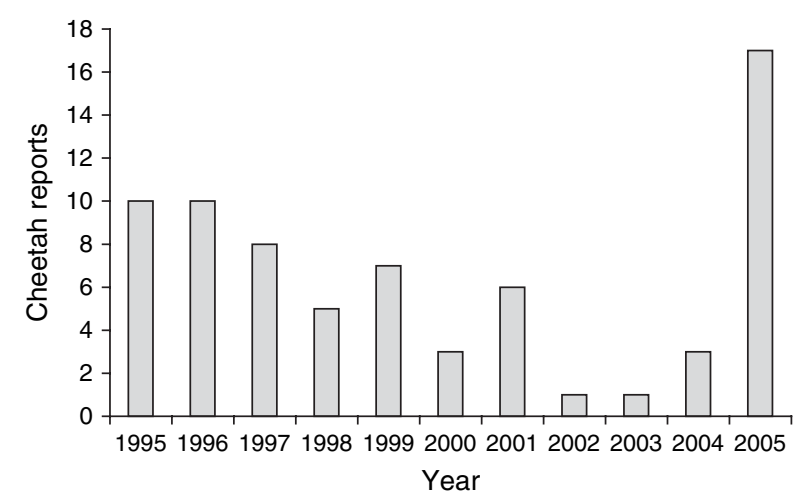

FIG. 7 Number of cases of cheetah depredation on livestock in Ghanzi District (Fig. 1) reported to the Department of Wildlife and National Parks during 1995-2005. Compensation was given in 1995, 1996 and 2005. 
their farms. Studies in Namibia have shown that the cheetah is not a regular livestock predator (Marker et al., 2003c). Most cheetah sightings in Ghanzi were reported on private farms. This may support the speculation that private farmers in Ghanzi District face high conflict with cheetah. Furthermore, farmers with game lost more livestock than those without game. This is consistent with the finding by Marker et al. (2003c) that game farms experience more cheetah problems because cheetah are attracted to game as their natural prey. The higher number of cheetah sightings in communal lands than in wildlife management areas may not necessarily mean there are more cheetah there. The sightings of cheetah in wildlife management areas were concentrated within the farming areas, which represent $<30 \%$ of the areas, whereas sightings by communal land farmers were almost evenly distributed over the area.

Seventy-six percent of farmers supported cheetah conservation in general but the support decreased to $50 \%$ beyond protected areas. This suggests that many farmers support cheetah conservation only in areas where the species will not come into conflict with their farming interests. Better educated farmers were more positive towards cheetah conservation, and awareness of the values of conservation usually increases with education (Williams et al., 2002; Ericsson \& Heberlein, 2003). However, when considering cheetah conservation beyond protected areas, education did not have a significant influence on support but land-use type did. Farmers in both wildlife management areas and private farms were relatively more supportive. Community-based natural resource management programmes are practised in the wildlife management areas (Twyman, 2000; DWNP, 2004) and more private farmers are venturing into game farming and tourism-oriented projects such as lodges (NCSA, 1998). These farmers are therefore expected to have more appreciation of the value of cheetah for tourism.

The farmers' tribe was also significant in influencing support for cheetah conservation beyond the protected areas. The Baherero and Bakgalagadi were more negative than the Basarwa and others. However, the tribes' distribution in relation to land-use types was not random, such that the effect of tribe could not be clearly separated from that of land-use type. The Basarwa are the dominant tribe in wildlife management areas, the Bakgalagadi in communal lands, and the Baherero in both private farms and communal lands. Other tribes and groups dominated on private farms. The Basarwa are traditionally hunters and gatherers, and own relatively few livestock compared to other tribes. This may explain why they have less conflict with predators. The Bakgalagadi and the Baherero are neither directly involved in game farming nor in community-based natural resource management, and are mostly cattle and small-stock farmers.
Private farmers were more positive than other farmers, even though a higher proportion of them had lost livestock to cheetah and they observed the most cheetah. Therefore, there was no evident link between the level of livestock depredation attributed to cheetah and support for cheetah conservation. Other studies also have found that previous negative experiences with wildlife may not necessarily influence farmers' support for its conservation (Hill, 1998; Conforti \& de Azevedo, 2003).

Farmers with game on their farms were more supportive of cheetah conservation than farmers without game, despite the fact that game losses to predators were not compensated, indicating that game farming can be an important land-use practice. However, the fact that game farmers cannot be compensated for the game killed by cheetah and that they suggested cheetah should be restricted to protected areas or that safari hunting should be allowed to control cheetah numbers, may be a potential threat to the future of cheetah in these areas. Marker-Kraus et al. (1996) reported that the killing of cheetah for the protection of game and livestock was a major threat to the species' survival in Namibia.

The number of reports received by the Department of Wildlife and National Parks about livestock depredation by cheetah was higher during the compensation period than at other times. Farmers considered that there was no reason to report losses when there was no compensation, the Department's offices were far, or that proof that depredation had occurred was often not satisfactory to convince the authorities. This was also supported by the finding that the jackal was rated as the second most important predator by farmers, which was not consistent with the Department's database. Paying compensation could help the government to understand better the extent of depredation by cheetah. Parry \& Campbell (1992) and Jackson et al. (2008) advocated providing adequate compensation schemes in Botswana to reduce human-wildlife conflicts. However, the literature suggests that compensation schemes, although popular and meant to increase tolerance for losses (Naughton-Treves et al., 2003; Breitenmoser et al., 2005), seem to be ineffective in reducing conflicts or increasing the level of tolerance (Wagner et al., 1997; Ciucci \& Boitani, 1998; Naughton-Treves et al., 2003; Swenson \& Andrén, 2005). It is also easy for governments to become trapped into compensation schemes indefinitely (Wagner et al., 1997). Therefore, although an expanded compensation programme would give more accurate information on losses to cheetah, it is important that the government weigh the costs and benefits of such an action carefully (Jackson et al., 2008) to determine whether the information is worth the long-term cost.

In summary, the cheetah is reported to cause substantial livestock losses, although is is not the major livestock predator in Ghanzi District. Despite problems caused by 
cheetah, farmers were generally supportive of cheetah conservation. However, some farmers want them to be contained within protected areas. Compensation helps managers understand the extent and nature of the conflict between farmers and cheetah. Education about livestock depredation by other predators, mitigation measures, and involvement of farmers through a participatory approach to planning and decision-making about predator management could enhance the farmers' sense of conservation responsibility and improve farmers' attitudes towards cheetah conservation beyond protected areas. Currently the Western Kgalagadi Corridor Conservation Project of Conservation International is trying to promote connectivity between Kgalagadi Transfrontier Park and Central Kalahari Game Reserve. This project, which also involves NGOs such as Cheetah Conservation Botswana, has a human-wildlife conflict component in which threats to predators such as cheetah and wild dogs are addressed.

\section{Acknowledgements}

We would like to thank the Department of Wildlife and National Parks for allowing us to use the Problem Animal Control data for part of this paper. Ellen Sandberg and Svein Solberg assisted with statistical analysis. France Malebogo Magowe provided accommodation during the fieldwork. Amy Dickman and an anonymous referee improved the manuscript.

\section{References}

Botswana Government Gazette (1996) Cab Directive 17/96: Amendment of Section 46 of the WCNPA 28 of 1992. Government of Botswana, Gaborone, Botswana.

Botswana Government Gazette (2000) Statutory Instrument No. 69 of 2000 Restricting the Killing of Lions and Cheetahs by both Public and Wildlife Staff. Ministry of Commerce and Industry, Government of Botswana, Gaborone, Botswana

Breitenmoser, U., Angst, C., Landry, J., BreitenmoserWursten, C., Linnell, J.D.C. \& Weber, J. (2005) Non-lethal techniques for reducing depredation. In People and Wildlife: Conflict or Coexistence? (eds R. Woodroffe, S. Thirgood \& A. Rabinowitz), pp. 49-71. Cambridge University Press, Cambridge, UK.

Broomhall, L.S., Mills, M.G.L. \& Du Toit, T.J. (2003) Home range and habitat use by cheetahs (Acinonyx jubatus) in the Kruger National Park. Journal of Zoology, 261, 119-128.

Caro, T.M. \& Durant, S.M. (1995) The importance of behavioural ecology for conservation biology: example from Serengeti carnivores. In Serengeti II (eds A.R.E. Sinclair \& P. Arcese), pp. 451-472. The University of Chicago Press, Chicago, USA.

Ciucci, P. \& Boitani, L. (1998) Wolf and dog depredation on livestock in central Italy. Wildlife Society Bulletin, 26, 504-514.

Conforti, V.A. \& De Azevedo, F.C.C. (2003) Local perception of jaguars (Panthera onca) and pumas (Puma concolor) in the Iguaçu National Park area, south Brazil. Biological Conservation, 111, 215-221.
DLUPU (District Land Use Planning Unit) (1995) Ghanzi District Land Use Zoning Plan (Ghanzi District: Land Use Planning Unit). Government of Botswana, Ghanzi, Botswana.

Durant, S. (1998) Competition refuges and coexistence: an example from Serengeti carnivores. Journal of Animal Ecology, 67, 81-92.

Durant, S.M., Kelly, M. \& Caro, T.M. (2004) Factors affecting life and death in Serengeti cheetahs: environment, age, and sociality. Behavioural Ecology, 15, 11-22.

DWNP (Department of Wildlife and National Parks) (2004) Ghanzi District Annual Report. Unpublished Report. DWNP, Ghanzi, Botswana.

Ericsson, G. \& Heberlein, T.A. (2003) Attitudes of hunters, locals, and the general public in Sweden now that wolves are back. Biological Conservation, 111, 149-159.

GoB (Government of Botswana) (1992) Wildlife Conservation and National Parks Act no. 28 of 1992. Botswana Government Print, Gaborone, Botwana

Hill, C.M. (1998) Conflicting attitudes towards elephants around the Budongo Forest Reserve, Uganda. Environmental Conservation, $25,244-250$.

IUCN (2007) 2007 IUCN Red List of Threatened Species. IUCN, Gland, Switzerland. Http://www.redlist.org [accessed 30 January 2008].

Jackson, T.P., Mosojane, S., Ferreira, S.M. \& van Aarde, R.J. (2008) Solutions for elephant Loxodonta africana crop raiding in northern Botswana: moving away from symptomatic approaches. Oryx, 42, 83-91.

Kelly, M.J. \& Durant, S.M. (2000) Viability of the Serengeti cheetah population. Conservation Biology, 14, 786-797.

Laurenson, M.K. (1994) High juvenile mortality in cheetahs (Acinonyx jubatus) and its consequences for maternal-care. Journal of Zoology, 234, 387-408.

MARKER, L. (2000) 1999 International Cheetah (Acinonyx jubatus) Studbook. Cheetah Conservation Fund, Otjiwarongo, Namibia.

MAR KER, L. (2002) Aspects of Namibian cheetah (Acinonyx jubatus) biology, ecology and conservation strategies. $\mathrm{PhD}$ thesis, University of Oxford, Oxford, UK.

Marker, L.L., Dickman, A.J., Jeo, R.M., Mills, M.G.L. \& Macdonald, D.W. (2003a) Demography of the Namibian cheetah, Acinonyx jubatus jubatus. Biological Conservation, 114, 413-425.

Marker, L.L., Dickman, A.J., Mills, M.G.L. \& Macdonald, D.W. (2003b) Aspects of the management of cheetahs, Acinonyx jubatus jubatus, trapped on Namibian farmlands. Biological Conservation, 114, 401-412.

Marker, L.L., Mills, M.G.L. \& Macdonald, D.W. (2003c) Factors influencing perceptions of conflict and tolerance towards cheetahs on Namibian farmlands. Conservation Biology, 17, $1290-1298$.

Marker, L.L., Muntifering, J.R., Dickman, A.J., Mills, M.G.L. \& MACDONALD, D.W. (2003d) Quantifying prey preferences of free-ranging Namibian cheetahs. South African Journal of Wildlife Research, 33, 43-53.

Marker-Kraus, L., Kraus, D., Barnett, D. \& Hurlbut, S. (1996) Cheetah Survival on Namibian Farmlands. Cheetah Conservation Fund, Windhoek, Namibia.

Mills, M.G.L. (1991) Conservation and management of large carnivores in Africa. Koedoe, 34, 81-90.

Naughton-Treves, L., Grossberg, R. \& Treves, A. (2003) Paying for tolerance: rural citizens' attitudes toward wolf depredation and compensation. Conservation Biology, 17, 1500-1511.

NCSA (National Conservation Strategy Coordinating Agency) (1998) National Report on Measures Taken to Implement the 
Convention on Biological Diversity: Fourth Conference of Parties to the CBD in Bratislava, Republic of Slovakia. Government of Botswana, Gaborone, Botswana.

Parry, D. \& Campbell, B. (1992) Attitudes of rural communities to animal wildlife and its utilization in Chobe Enclave and Mababe Depression, Botswana. Environmental Conservation, 19, 245-252.

Patterson, B.D., Kasiki, S.M., Selempo, E. \& Kays, R.W. (2004) Livestock predation by lions (Panthera leo) and other carnivores on ranches neighbouring Tsavo National Parks, Kenya. Biological Conservation, 119, 507-516.

Purchase, G.K. \& DU Toit, T.J. (2000) The use of space and prey by cheetahs in Matusadona National Park, Zimbabwe. South African Journal of Wildlife Research, 30, 139-144.

SWEnSON, J.E. \& ANDRÉN, H. (2005) A tale of two countries: large carnivore depredations and compensation schemes in Sweden and Norway. In People and Wildlife: Conflict or Co-existence? (eds R. Woodroffe, S. Thirgood \& A. Rabinowitz), pp. 323-339. Cambridge University Press, Cambridge, UK.

Tнома , D.S. (2002) Sand, grass and ... cattle: the modern Kalahari environment. In Sustainable Livelihoods in Kalahari Environments: Contributions to Global Debates (eds D. Sporton \& D. Thomas), pp. 21-38. Oxford University Press, New York, USA.

Twyman, C. (2000) Participatory conservation? Community-based Natural Resource Management in Botswana. The Geographical Journal, 166, 323-335.

TwYMAN, C. (2002) Entitled to a living: opportunity and diversity in the Wildlife Management Areas. In Sustainable Livelihoods in Kalahari Environments: Contributions to Global Debates (eds D. Sporton \& D. Thomas), pp. 130-159. Oxford University Press, New York, USA.

Wagner, K.K., Schmidt, R.H. \& Conover, M.R. (1997) Compensation programs for wildlife damage in North America. Wildlife Society Bulletin, 25, 312-319.
Williams, C.K., Ericsson, G. \& Heberlein, T.A. (2002) A quantitative summary of attitudes towards wolves and their reintroduction (1972-2000).Wildlife Society Bulletin, 30, 575-584.

Witmer, G., Rodriguez, B.M. \& Voughan, C. (1995) Aspects of felid predator control and conservation in Costa Rica. In Integrating People and Wildlife for a Sustainable Future. Proceedings of the First International Wildlife Management Congress (eds J.A. Bissonette \& P.R. Krausman), pp. 398-401. The Wildlife Society, Bethesda, USA.

\section{Appendix}

The appendix for this article is available online at http:// journals.cambridge.org

\section{Biographical sketches}

Moses Selebatso is a wildlife ecologist with a particular interest in human-wildlife conflict and wildlife management. He is currently District Head of the research division of Department of Wildlife and National Parks of Botswana, in Ghanzi District, and is responsible for coordination of wildlife research in the District. S TEIN R. Moe is a wildlife ecologist with particular interests in wildlife management and plant-animal interactions, and has been involved in research projects in several African and Asian countries. JON E. SWENSON is a wildlife ecologist. His major interest is the effects of human activities on wildlife populations. Although he has worked with a number of mammal and bird species on four continents, his primary research concerns the ecology and management of large carnivores. 